\title{
HISTORIA, RAZÓN DE ESTADO Y BUROCRACIA. ANTONIO DE SOLÍS CONTRA JERÓNIMO MASCARENAAS (1662-1663)
}

\section{UNA ESCARAMUZA LITERARIA}

Entre las raras excepciones en que la documentación de archivo aporta una información sustancial a la biografía propiamente literaria de autores seiscentistas, aunque sólo sea en los aspectos más sórdidos de una guerra literaria de tono menor, se encuentran los datos que vamos a extractar aquí. El caso puede resultar tanto más ejemplar por ser uno de sus protagonistas don Antonio de Solís y Rivadeneyra, gran escritor del Barroco crepuscular y uno de los pocos autores del XVII tardío que cuenta con estudios biográficos fiables y excepcionalmente rigurosos, gracias a la tenacidad y ejemplar dedicación de Luis A. Arocena ${ }^{1}$ y Frédéric Serralta ${ }^{2}$. Aunque ambos contaban con precedentes nada desdeñables, que incluyen una biografía apologética escrita por un admirador próximo de Solís 3 , o la correspondencia con hombres de letras coetáneos publicada ya por Mayans en el siglo $\mathrm{XVIII}^{4}$, es mucho lo que ha podido añadirse de primera mano

${ }^{1}$ Antonio de Solís, Cronista indiano. Estudio sobre las formas historiográficas del Barroco, EUDEBA, Buenos Aires, 1963.

2 "El testamento de Antonio Solís y otros documentos biográficos", Criticón, 1979, núm. 7, 1-57; y "Nueva biografía de Antonio Solís y Rivadeneyra”, Criticón, 1986, núm. 34, 51-157.

${ }^{3}$ Juan de Goyeneche, "Vida de don Antonio de Solís y Ribadeneyra, Oficial de la Secretaría de Estado, Secretario de su Magestad, y su Coronista Mayor de las Indias”, en Varias poesías sagradas y profanas de Solís (Madrid, 1692). Cierto que esta "Vida" contiene poca información objetiva. J. LucIE-LARY se lamentaba ya de "le peu de substance" que puede extraerse de "l'indigeste fatras" del escrito de Goyeneche, en la "Biographie de Solís" que precede a su ed. abreviada de la Historia de la Conquista de Méjico, Garnier, Paris, 1897, p. vi.

${ }^{4}$ Cartas de don Nicolás Antonio y de don Antonio de Solís (Lyon, 1733); reed. por E. de Ochoa, Epistolario español, BAE, t. 13, 1872, pp. 582-592. 
para reconstruir sobre bases sólidas la biografía de Solís tanto en su entorno familiar como en su carrera profesional de secretario regio y cronista de Indias. No es, pues, Solís un autor desconocido al margen de su obra literaria, ni un personaje histórico sin biografía verificable. Y sin embargo, descontando las noticias sobre su persona que aparecen en vejámenes literarios, y que hay que tomar con las lógicas reservas, o las muy vagas que atañen a la preparación y edición de su Historia de la conquista de México ya muy al final de su vida, las informaciones sobre Solís en cuanto escritor que pueden extraerse de una documentación tan laboriosamente reunida son, sencillamente, inexistentes. Más en concreto, en los años que suceden a su nombramiento como cronista de Indias (enero de 1661), Serralta deduce, con toda justeza a partir de los datos disponibles, que la vida de Solís se desenvolvía dentro de "una gran estabilidad", y en lo que atañe a las letras nada consta en ese período decisivo que va "de la reconversión [en cronista de Indias] a la ordenación [sacerdotal] (1660-1667)"5. Pronto veremos que esa estabilidad no excluía algún conflicto grave ocasionado, precisamente, por las letras humanas, o demasiado humanas.

El antagonista de nuestra historia, don Jerónimo Mascareñas, es hoy en el mejor de los casos simple objeto de erudición. La gratitud retrospectiva de varios historiadores actuales y pretéritos que se han ocupado del siglo XVII debiera bastar para sacarlo del limbo de los autores olvidados. Mascareñas reunió una de las más copiosas, útiles y utilizadas colecciones de documentos que se conocen para quien tenga que habérselas con los reinados de Felipe III y Felipe IV. Los cincuenta volúmenes de tomos de "varios", conservados en la Biblioteca Nacional de Madrid (ms. 2343 a 2393), con el nombre de "Colección de Sucesos" o "Colección Mascareñas" son, en efecto, una fuente inagotable de manuscritos e impresos que permiten seguir los avatares militares y políticos de la monarquía hispánica en todos sus frentes; especialmente valiosa es la documentación sobre la guerras de Cataluña, Portugal, Italia y Flandes, las relaciones diplomáticas con el Imperio, etc.; pero apenas habrá suceso histórico de algún interés entre 1598 y 1666 que no aparezca reflejado en estos tomos ${ }^{6}$.

${ }^{5}$ F. Serralta, "Nueva biografía...”, pp. 99-107.

${ }^{6} \mathrm{El}$ inventario de la colección ocupa todo el volumen de Julián PAZ, Catálogo de "tomos de varios", Biblioteca Nacional, Madrid, 1938. 
Esa masa documental, sin embargo, es sólo una parte de los papeles que Mascareñas había reunido con la mira puesta en la redacción de una gran Historia que no llegó a concluir. Ese objetivo incumplido lo alternó Mascareñas con la publicación de un buen número de obras, y el proyecto de varias otras. Al dar a la imprenta en 1650 su primer libro, el Viaje de la Sereníssima Reyna Doña María Ana de Austria, Mascareñas ofrece un catálogo de los libros que tenía ya terminados y que alcanzan la respetable cifra de 31 títulos. Súmense varios otros que escribió en los años que mediaron hasta su muerte, en 1671. Sólo una mínima parte de todas esas obras fueron publicadas, y algunas más lo serían ya en época muy posterior a su muerte. De todo el conjunto de la obra historiográfica de don Jerónimo puede concluirse que nos hallamos ante un historiador de la misma escuela y vitola que su contemporáneo Pellicer y Tovar, con quien mantuvo excelentes relaciones: la misma grafomanía enciclopédica, la misma inclinación por la genealogía o la hagiografía, una análoga mixtura de interés por el pasado más remoto coexistente con el memorialismo contemporáneo sin desdeñar el panfleto al servicio de la política del momento, y una idéntica fascinación ante el monarca y la dinastía de quien ambos fueron leales súbditos. Póngase, sin embargo, en el haber de Mascareñas su mayor positivismo y menores concesiones a la fabulación al tratar de la Historia antigua, y, sobre todo, un espléndido manejo literario de la lengua castellana que hace de él uno de los más notables prosistas que pueden leerse de toda la segunda mitad del siglo $\mathrm{XVII}^{7}$.

${ }^{7}$ Mascareñas ha merecido muy escasa atención, y en trabajos de poca entidad. El apellido común parece ser la razón única de las breves notas de Carlos Eugenio Mascareñas, "El obispo de Segovia D. Jerónimo Mascareñas y sus obras de Historia”, RBD, 1 (1947), 17-28; "D. Jerónimo Mascareñas, historiador de la campaña de Portugal en Extremadura (1662)", REE, 1944, 437-439; y "Cataluña y Portugal. Notas bibliográficas. (Siglo XVII)", Instituto, 1935, núm. 89, 181-185. ROBERT RiCARD ha extraído información útil de una de las obras de Mascareñas, la Historia de Ceuta, publicada sólo en el siglo xx (ed. A. de Dornelas, Universidad de Coimbra, 1918); cf. "Une description du Habt en 1648. (Traduction de quelques pages de l'Historia de la Ciudad de Ceuta de Jerónimo de Mascarenhas)", Hesperis, Paris, 1937, núm. 3; y "Latin Olea, Touareg et Portugais Aleo. Hypotheses et Rapprochements", BHi, 63 (1961), 179-185. Modernamente se ha reimpreso también (Jerez de la Frontera, 1981) su obra Fray Juan Pecador, religioso del orden y hospitalidad de S. Juan de Dios..., Melchor Alegre, Madrid, 1665. 
Pertenece Mascareñas al grupo de aristócratas portugueses que permanecieron fieles a Felipe IV en el momento de la insurrección de 1640. Hijo del virrey del Brasil y hermano del marqués de Montalvão y conde de Castilnovo, su fidelidad no tuvo, a juzgar por su obra y su carrera vital, ninguna sombra de vacilación como las que sí pueden presumirse en uno de sus más célebres amigos y coetáneos, el todavía más polígrafo Manuel Faria e Sousa ${ }^{8}$. La lealtad de Mascareñas fue de las de primera hora: abandona Portugal al triunfar la rebelión, renunciando a sus puestos y bienes de fortuna; y no se vio alterada cuando su propio padre cambió de bando ${ }^{9}$. Muy cierto que su lealtad fue bien recompensada: fue Mascareñas caballero y definidor general de la Orden de Calatrava, y alcanzó todos los honores a que podía aspirar un segundón de familia ilustre: miembro del Consejo de Órdenes Militares y, después, del Consejo Supremo de Portugal, así como de la Junta General de competencias entre los Tribunales de la Monarquía, Sumiller de Cortina y Oratorio de su Majestad, etc. Todo ello sin perjuicio de una carrera eclesiástica no menos brillante: antes de dejar Portugal era ya doctor en Teología por la Universidad de Coimbra, canónigo de su catedral, y prior de Guimarães; después fue obispo electo de Leiria (obispado que, naturalmente, no llegó a ocupar), y, por último, obispo de Segovia. Don Jerónimo podía, seguramente con justicia, envanecerse de haber realizado su labor de historiador sin menoscabo de la dedicación a sus cargos públicos:

$8 \mathrm{Al}$ círculo de portugueses afincados en la corte de Madrid con quienes Mascareñas mantuvo relación amistosa pertenece también el conocido poeta y autor teatral Juan de Matos Fragoso, que contribuye con un buen soneto laudatorio a la edición de la Campaña de Portugal.

${ }^{9}$ En la dedicatoria de Amadeo de Portugal, en el siglo Juan de Meneses... (1653), Mascareñas traza una pequeña autobiografía y refiere su fuga de Portugal a Castilla. Sobre su venida y la de otros portugueses se hace, en cambio, un comentario sarcástico en una carta denigratoria contra el Conde Duque escrita por "un cortesano de Madrid" en abril de 1642: "Aquí se nos han venido un conde de Taro[u]ca, y un fulano Barrabás y otros locos, lunares de sí mismos. S. M. los ha recibido bien por gusto del Conde, y si fuera por el mío, ya ellos estuvieran ahorcados por leales y traidores, y murieran con un título más", Cartas de algunos PP. de la Compañia de Jesús, Imp. Nacional, Madrid, 1862, t. 4, p. 329. En agosto de 1643 denunció, junto con Pellicer, y evitó el intento de varios eclesiásticos portugueses de regresar a su patria junto con varios criados para, como se pudo comprobar, ponerse al servicio de João IV (ibid., 1863, t. 5, pp. 203-204); el mismo relato figura en los Avisos, de Pellicer, ed. en Semanario Erudito, 33 (1790), pp. 51-52. 
"Puedo asegurar confiadamente que tanto tiempo aplicado a la curiosidad no se hurtó a las ocupaciones de los puestos, sino al sueño, al descanso, y a los entretenimientos de la vida" 10 .

La fidelidad a Felipe IV no restaba nada a su orgullo de portugués arquetípico ni a su interés por los fastos y glorias de su tierra natal. Cabe afirmar, incluso, que latía en Mascareñas, como en varios de los lealistas filipinos portugueses de su generación, un profundo desprecio por el "plebeyismo" que sustentaba el éxito - transitorio para ellos- de la traición del tirano y usurpador — claro es que también según ellos- João IV de Bragança. Entre las obras conservadas o perdidas que escribió Mascareñas son mayoría las que se ocupan de historia específicamente portuguesa: Libro de familias de Portugal, Libro das linhagens do Reino de Portugal, Historia de la ciudad de Coimbra, Genealogía Regia de Portugal, Varones ilustres portugueses, Descripción de Portugal y sus conquistas, Historia de las Órdenes militares de Portugal, Vida de S. Isabel reina de Portugal, etc., etc. Especialmente sensible es la pérdida, definitiva al parecer, de una obra dedicada al Origen de la Inquisición en Portugal, en la que se refutaba "con papeles originales y Bulas pontificias el embuste introducido entre los poco noticiosos"; claro es que tal embuste alude a la estupenda fábula del Falso Nuncio de Portugal que siguió siendo creída a pie juntillas por una mayoría de historiadores hasta mucho tiempo después. Su dedicación a la historia portuguesa no fue nunca incompatible con su decidido rechazo a los restauradores de la independencia de Portugal, en quienes sólo veía a unos desleales aventureros abocados al fracaso. Sirva de muestra el título completo de su obra de más aliento: Historia de la ciudad de Ceuta (única plaza de Portugal y sus conquistas que conservó la debida obediencia al Rey Nuestro Señor), sus sucesos militares y políticos.

Es también una obra histórica referente a Portugal la que ocasionó a Mascareñas el mayor contratiempo de su vida como escritor, y la que le llevó a enfrentarse con Antonio de Solís. Anticipemos ya que el asunto se resolvió, finalmente, de forma favorable para Mascareñas, y que en el enfrentamiento de ambos historiadores el papel del "villano" corresponde sin duda a Solís. Ese es, al menos, el dictamen al que llegará cualquier lector de los alegatos de ambas partes, que por azar se nos han conservado en archivos distintos, el de Simancas y el Histórico

10 Dedicatoria de la Apología histórica por la ilustríssima Religión y Ínclita Cavallería de Calatrava, D. Díaz de la Carrera, Madrid, 1651. 
Nacional de Madrid. Que Mascareñas fuera el agraviado, no quiere decir que aceptase con mansedumbre el agravio; muy al contrario y como veremos, su autoexculpación incluía ataques de gran calado contra Solís, y procuró devolver con creces la ofensa recibida, haciendo insinuaciones contra su émulo que apuntaban al crimen laesae majestatis, además de, entre otras lindezas, negar sus capacidades como cronista y manifestarse despectivamente a propósito de la actividad de Solís como dramaturgo.

\section{AprobaCión PÚBLICA Y “DILIGENCIA SECRETA”}

La obra que motivó tan encarnizadas hostilidades era una crónica amplia escrita por Mascareñas sobre la campaña dirigida por don Juan José de Austria para recuperar Portugal en 1662. Era lógico el interés del historiador, portugués y miembro del Consejo de Portugal, por la reanudación del esfuerzo bélico en la frontera de Extremadura y Alemtejo, tras varios años de inactividad en los que la acuciada Monarquía pudo prestar pocas atenciones a la sedición portuguesa. En su dedicatoria dirigida al propio Rey, Mascareñas valoraba la campaña de 1662 menos por los éxitos militares que se obtuvieron, en verdad muy escasos, que como prueba de un designio que a más largo plazo devolvería a unos vasallos ingratos al redil de Felipe IV. Nada podía hacer prever que un libro semejante pudiera ser considerado inoportuno; sin embargo, el autor se encontró con la desagradable sorpresa de que se le ordenaba paralizar su publicación. La reacción de Mascareñas, que supo bien de qué aljaba salía la flecha, y la vindicación de su obra, doblada en ataque al denunciante, constan en un memorial autógrafo [A.H.N., Madrid, Estado, leg. 777] dirigido al rey que bien merece ser reproducido en su integridad:

\section{Señor}

Don Luys de Oyanguren me dixo de parte de V Mgd que antes de publicar el libro, que escriví de la campaña última de Estremadura, es V Mgd servido de que yo se le remitta, para que se vea si ay algún reparo en él. Respondíle que por no estar todavía acabado de imprimir no obedecía luego la orden de $\mathrm{V} \mathrm{Mgd}$, mas que, como estuviesse concluyda la obra, lo executaría con todo el rendimiento. 
Pongo agora el libro acabado en las Reales manos de V Mgd, con declaración que imprimí mil y quinientos cuerpos, y estos estoy pronto para entregarlos a la persona que $\mathrm{V} \mathrm{Mg}$ duere servido, para que se pueda quemar la impressión de una vez, si se hallare algún impedimiento en este libro.

Con esta ocasión me pareció representar a V Mgd que en todas mis acciones he procurado no desviarme del camino ordinario; y en el particular de los muchos libros que he impresso, no ha aparecido hasta aora alguno de impressión de Aragón, ni de Flandes, ni de Italia. Todos se imprimieron en esta Corte con las licencias del Ordinario y del Consejo, en la forma que lo mandan las leyes de estos Reynos; y por la misericordia de Dios ninguno asta aora se ha prohibido, porque pongo todo el cuydado en escrivirlos como gran Católico, como gran vasallo, y como gran cavallero; y así cumplo bien con Dios, con V Mgd, y conmigo.

En éste de la campaña de Estremadura he procedido aun con más atención, porque mucho antes de resolverme a imprimirle le puse en las manos del señor Don Juan para que viesse si estava en forma conveniente. Restituyómele S. A. no solamente emendado de su misma letra, como se vee en el original, sino también con dos pliegos de advertencias, que miran al hecho, y en cuya emienda obedecí enteramente a S. A. Después de esta diligencia, y de carta de $\mathrm{S}$. A. en que me dize que este libro está escrito con grande estilo y maestría, y que es digno de que se imprima en mi nombre, passé a las demás diligencias, sacando las licencias del Ordinario y del Consejo, y privilegio firmado de V $\mathrm{Mg}^{\mathrm{d}}$, y con esto di principio a la impressión.

La persona a quien le remitió el Consejo fue Don Antonio Solís, oficial del de Estado y coronista de las Indias, el qual le aprobó con las alabanças que $\mathrm{V} \mathrm{Mg}$ d puede mandar ver en su Aprobación, y en ella se fundó la licencia del Consejo y privilegio de $\mathrm{V} \mathrm{Mg}$. Después de haver hecho Don Antonio esta acción, que es la que mira a la fee pública, hizo otra muy contraria, y que al crédito de la misma fee pública tiene grandes inconvenientes en que se admita; y es que públicamente se anda alabando de que, aunque aprobó este libro, está interpuesta una diligencia secreta, con que no saldrá a luz. Y viendo yo por una parte esta jactancia suya, y por otra que V Mgd me manda suspenda la publicación, tengo bastante fundamento para creer que esta calumnia nace del mismo Don Antonio Solís.

Assí, es preciso dezir a V Mgd que quando hablé a Don Antonio en que me despachasse con brevedad la censura, reconocí en él tenía muy poco afecto a que se publicasse este buen sucesso contra el Duque de Bergança, haziéndome algunos reparos muy mal sonantes de quien es (como él entonces me dixo) 
oficial de la Secretaría de Estado. Confiesso a V Mgd, y afirmo como sacerdote, que fue la primera vez que tuve noticia de que lo era, y que fue una de las novedades que me hizieron mayor dissonancia, porque yo no podía presumir que un criado de suma confidencia del conde de Oropesa, imediato sucessor del Duque de Bergança, esté metido dentro de la Secretaría de Estado de la parte de España, manejando los papeles corrientes de Portugal, y siendo dueño de las noticias de Estado de toda Europa y de las correspondencias de los Embaxadores, en tiempo que todas las negociaciones se dan la mano con las materias de Portugal. No hay, Señor, pocos exemplares en el mundo de los malos efetos que han produzido semejantes confianças, ni es dificultoso dar un desvío a este peligro sin ruydo, haviendo tantas plaças de oficiales en tantos otros Consejos, y siéndole más natural la de Indias a quien es Coronista de aquella parte.

En lo que toca a este libro, $\mathrm{V} \mathrm{Mgd}$ mande lo que fuere de su mayor servicio, que yo no atiendo a otro fin; y como he dicho, estoy pronto para entregar toda la impressión a la persona que $\mathrm{V} \mathrm{Mgd}$ se sirviere de señalarme. Pero no escuso de representar a V Mgd que es parte de la dicha de los Reyes que hombres de mi calidad, de mi graduación y de mi zelo se apliquen a escrivir sus sucessos, porque con estas calidades llevan vencido el crédito común, no solamente entre los vasallos sino también entre las Naciones. Y no parece conveniente que quando esto se haze por gusto y no por interés, se salga un particular con impedirme un libro ya impresso con todas las circunstancias que mandan las leyes de estos Reynos, de que se seguirá tal ruydo que piensen muchos que escrivo en él algo contra $\mathrm{V} \mathrm{Mgd}$. Porque además de que la intención de Don Antonio es cierto que en este caso no es zelo del servicio de $\mathrm{V} \mathrm{Mg}{ }^{\mathrm{d}}$ sino antes muy perjudicial a él, su inteligencia en las materias de la Historia es sumamente corta, y en ninguna manera es ascenso natural passar de los chistes de las Comedias, que es su professión, al puesto de Coronista de un tan gran Monarca, empleo de tanta suposición entre los señores Reyes antiguos de estos Reynos que repetidas vezes eligieron para esta ocupación a los Arçobispos de Toledo, y en falta suya a otros Prelados y grandes cavalleros, a quien se fían seguramente la posteridad y fama de los Reyes.

Yo, Señor, he procurado siempre merecer a V Mgd las honras que repetidamente experimento de su real grandeza; y ya que mi professión no me da lugar a servir a $\mathrm{V} \mathrm{Mg}^{\mathrm{d}}$ con la espada, me he aplicado a hazerlo con la pluma, porque me causa gran dolor lo que leo en los libros estrangeros, y no merece desayres quien procura volver por el crédito de las acciones de su Rey. En esto me empleo todo el tiempo que me sobra de mis ocupacio- 
nes, y se ha luzido tanto mi trabaxo que los que han visto lo que yo tengo escrito del Reynado de $\mathrm{V} \mathrm{Mg}$ se admiran de que sea tarea de una sola vida. Pero si basta para dar con esta máchina en tierra un tan flaco instrumento, entenderé que es permissión de Dios que al tiempo que los enemigos de esta Monarchía están publicando sus sucessos tan contra la verdad, se pongan estorvos acá a quien quiere volver por ella, y alçaré yo la mano de mi trabaxo sin mostrarme quexoso; antes, entendiendo que esto conviene más al servicio de $\mathrm{V} \mathrm{Mg}^{\mathrm{d}}$ y que havrá en esta Monarchía muchos sujetos, no que con más zelo sino que con mayor inteligencia den a estas materias la sazón de que ellas bien necessitan.

Guarde Dios la Católica y Real persona de V Mgd, como la Christiandad ha menester y sus vasallos deseamos. Madrid a 24 de Febrero de 1663.

Don Gerónimo Mascareñas, obispo electo de Leyria.

Descontando las exageraciones que puedan deberse al orgullo lastimado y a la excelente opinión que don Jerónimo tenía de sí mismo, con sus ribetes inclusos de portugués "finchado", el alegato de Mascareñas respondía a la verdad en todo cuanto es posible verificar sus afirmaciones. Es, desde luego, fácil de comprobar que sus libros anteriores se habían impreso en Madrid y con todas las formalidades, aunque tampoco había mucho motivo para jactarse de que ninguno de ellos fuese "de impressión de Aragón, ni de Flandes ni de Italia", ni hubiese sido prohibido. Pocas heterodoxias podían tener cabida en obras dedicadas a exaltar la Historia (1651) o exponer las Definiciones (1661) de la orden de Calatrava, o en las consagradas a las biografías apologéticas del fundador de la misma orden, Raymundo Abad de Fitero (1653) y la de Amadeo de Portugal... religioso de la Orden de S. Francisco (1653), fundador también de una congregación religiosa. Ninguna necesidad tenía el autor de encaminar tales obras a otros reinos de la Monarquía con normas más laxas en lo que a impresión de libros se refiere.

Mayor interés tiene la afirmación de que su crónica de la campaña portuguesa había pasado la censura previa de su máximo protagonista, don Juan de Austria. Se conserva, en efecto, el manuscrito que sirvió para la impresión de la obra (B.N. ms. 6242), acribillado de tachaduras y añadidos de diferentes letras, hasta el punto de que puede hablarse en varios capítulos de una nueva redacción o refundición de la obra.

La doblez que Mascareñas atribuye a Solís cuenta también con plena confirmación. Es cierto que, en lo que tocaba a "la 
fee pública”, don Antonio había examinado el libro por encargo del Consejo de Castilla, y que su aprobación, aun con los formulismos de rigor, no podía ser más elogiosa:

Aprobación de D. Antonio de Solís, Coronista mayor de su Magestad de los Reynos de las Indias.

De orden del Consejo he visto el libro intitulado Campaña de Portugal por la parte de Estremadura año de 1662, que escrivió el señor Don Gerónimo Mascareñas, Difinidor General de la Orden de Calatrava, del Consejo de su Magestad en el Supremo de Portugal; y no solo no hallo en él cosa que disuene a la Religión, o a las costumbres, pero entiendo que cederá en público beneficio el concederle la licencia que pide, para que salga a luz una obra grande por el argumento, grande por lo escrito, y grande por el Escritor: Assí lo siento. En Madrid a 29 de Enero de 1663. Don Antonio de Solís.

Pero es también verdad que don Antonio de Solís "sentía" de manera muy diferente, y que eran ciertos los rumores que llegaron a Mascareñas de que al mismo tiempo que Solís se deshacía en elogios, "se andaba alabando de que, aunque aprobó este libro, está interpuesta una diligencia secreta, con que no saldrá a luz". Grave error el de Solís, si aspiraba a ejercer de discípulo de Maquiavelo, al andarse con "jactancias" en mentideros públicos sobre diligencias secretas. Que Solís tenía poca capacidad para celar sus intenciones era cosa que se le había traslucido ya a Mascareñas: "Quando hablé a Don Antonio en que me despachasse con brevedad la censura, reconocí en él tenía muy poco afecto a que se publicasse este buen sucesso contra el Duque de Bergança, haziéndome algunos reparos muy mal sonantes".

Es el caso que la "diligencia secreta" en cuestión, y los "reparos muy mal sonantes" se nos conservan en sus términos literales por haber sido objeto de una deliberación del Consejo de Estado. Ello significa que la publicación del libro de Mascareñas se había convertido, Solís mediante, en cuestión de razón de Estado y que el órgano supremo de la Monarquía hispánica tuvo que tomar postura, y forzó al rey a tomarla, sobre lo que hoy nos parece un simple encontronazo entre colegas mal avenidos.

La consulta del Consejo de Estado no puede ser más explícita, ni más contraria a los intereses de don Jerónimo Mascareñas y su libro: 
[Consulta del Consejo de Estado] De ofiçio. En Madrid, a 5 de Abrill de 1663

El Consejo de Estado, concurriendo en él el Marqués de Velada, el Duque de Alba y el Marqués de Mortara. Sobre los reparos que se han hallado en un libro, que ha salido estos días, de la Campaña de Portugal por la parte de Estremadura del año de 1662, por Don Gerónimo Mascareñas.

Señor,

Teniendo presente el Consejo (en que concurrieron el Marqués de Velada, el Duque de Alba y el Marqués de Mortara) una orden de $\mathrm{V} \mathrm{Mg}^{\mathrm{d}}$ de [blanco, para una fecha que no consta] por la cual se sirve de mandar no se impriman libros que traten de suzessos de estos tiempos o guerras de ellos, sin que preceda exsamen y liçençia por esta vía [entiéndase, del propio Consejo de Estado], por el inconveniente que puede tener el que salgan a luz cosas que se opongan al punto de Estado. Y, al mismo tiempo, [teniendo presente el Consejo] el libro que va con esta consulta, dado a la estampa estos días por Don Gerónimo Mascareñas con título de Campaña de Portugal por la parte de Estremadura del año de 1662, que de acuerdo del Consejo se ha visto, y hallado en él los reparos contenidos en el papel incluso,

Es de pareçer que $\mathrm{V} \mathrm{Mg}$ se sirva de mandar recoxer luego este libro antes que se divulgue más, en atençión a lo sustancial de estas advertencias, representando a $\mathrm{V} \mathrm{Mgd}$ que, siendo servido de resolverlo assí, hará el Consejo, después de recoxido, más individual especulaçión para consultar con ella a $\mathrm{V} \mathrm{Mg}$ do que juzgare por conveniente, o en orden a que no vuelva a salir a luz, $\mathrm{o}$, en casso de salir, para representar todo lo demás que conviniere quitar demás de lo expresado; juzgando que el permitir que corriese assí fuera dexar crezer el daño, pues, aunque haya llegado a manos de yngleses este escrito, siempre les será de satisfaçión el saber que $\mathrm{V} \mathrm{Mgd}$ le ha mandado recoger, y por el contrario les fuera motivo justo de quexa y de sentimiento el disimular que corriese y se estendiese más. Y que juntamente se sirva $\mathrm{V} \mathrm{Mg}^{\mathrm{d}}$ de volver a mandar se observe con precissión la orden dada en esto por que se eviten inconvenientes semejantes, que son tan perjudiciales como se reconoçe al punto de Estado y real serviçio de $\mathrm{V} \mathrm{Mg}^{\mathrm{d}}$, que mandará lo que más fuere servido.

En Madrid a 5 de Abrill de 166[3].

Es claro que el Consejo se limitó a hacer suyos los argumentos del "Papel de reparos" que le había sido remitido contra el libro de Mascareñas, y que esos argumentos fueron suficientes para aconsejar al rey la orden, por lo pronto, "de mandar reco- 
xer luego este libro", y dejar la puerta abierta a prohibiciones más definitivas después de "más individual especulaçión". A estas alturas sabemos ya que esos reparos fueron formulados por Antonio de Solís y que constituyen la "diligencia secreta" de que ya tenía noticia el historiador portugués. Ese "Papel" fue copiado como documento adjunto a la consulta del Consejo de Estado; nos interesa transcribirlo aquí, y no sólo como muestra de la prosa que Solís sabía utilizar antes de consagrarse a la Historia de la conquista de México. Para obtener una versión lo más imparcial posible extractaremos en nota los párrafos del libro de Mascareñas que tan escandalosos parecieron a Solís [A. G. Simancas, Estado, leg. 2.679].

\section{[Papel de reparos]}

En la Secretaría de Estado de España hay Decreto de Su Magd. con fecha de [blanco] en que se sirve de ordenar que no se pueda ymprimir ningún libro que trate de historia de estos tiempos o suzesos de la Guerra de ellos sin que prezeda liçençia del Conssejo de Estado, por el incombeniente que puede tener el que se publiquen cosas que se opongan en algo al punto de Estado.

En un libro que ha salido estos días con título de Campaña de Portugal por la parte de Estremadura del año de 1662, escrito por Don Gerónimo Mascareñas, en el cual no ha precedido esta licencia de Estado, se hallan los reparos siguientes:

\section{Primer reparo. $1^{\circ}$}

El que se tiene por más principal es que con ocassión de referir este Author todo lo que passó en el casamiento de la hija del Rebelde con el Rey de Ingalaterra, y la entrega que se les hiço de la plaça de Tánger (lo cual trata dilatadamente desde la página 8 hasta la 16), cuenta en la página 10 y 11 que por el Rey nuestro señor se procuró el remedio del daño de esta entrega; y que para impedirlo se le previno desde Castilla a su gobernador, Don Luis de Almeyda, el descrédito que se le seguiría; y que para que obrara con más ensanche y sin más atençión que a su misma gloria, se le avisó que - abstrayendo del punto de la obediencia devida a su Rey y de la entrega de esta plaza a su verdadero dueño- tratase solamente de conservarla en la obediençia de la Iglesia cathólica, y que para esto se valiese de los socorros de los puertos de España, tan vezinos, porque en todos ellos había orden de socorrerle con bastimentos, muniçiones y dineros ${ }^{11}$. 
Y siendo assí que esta matheria se trató y manejó por Estado con summo secreto y con el recato nezessario a la gravedad de ella, pareze que se vienen tras los oxos los incombenientes de que este libro la haga notoria, pues aunque hubiese pasado con enemigos descubiertos nunca fuera açertado publicarla, por el prudente consejo de lo mucho que combiene que estén secretas las resoluçiones reservadas con que se gobiernan los negoçios contra los mismos enemigos. Y cuando se hiçiera pública por escritores estrangeros enemigos de Su Mgd también fuera de perjuicio, por ser con otra corona con quien se professa amistad; y aun quedara entonçes el recurso de que creyesen ser falsa la notiçia y divulgada de la embidia y de la emulaçión. Por todo lo cual, es de grave y conoçido inconveniente el que no sólo salga a la luz pública esta noticia, sino authorizada también con que la publique un escritor nuestro, y ministro de $\mathrm{Su} \mathrm{Mgd}$, que era a quien más tocaba paliarla coloreándola con pretextos que la desvaneziesen; lo cual se hubiera evitado con omitirlas (como se debía), y más no siendo en nada nezesaria para esta historia.

[Segundo reparo]. $2^{\circ}$

En el título de este libro se diçe: "escrito por D. Gerónimo Mascareñas. del Consejo de Estado de Su Mgd, y del supremo de Portugal, y jubilado en el de Órdenes", en que pareze que se excede, pues si digera "del Consejo de Estado de Portugal" no se hallara el reparo que se halla en dezir "del Consejo de Estado y del de Portugal”, porque la letra y colocada allí pareze que haze dos diferentes Consejos.

\section{[Tercer reparo]. $3^{\text {o }}$}

En la narrativa de lo de Tánger se diçe en la página 8 que como la contienda de los portugueses era con las armas cathólicas, llamaron en su favor las heréticas; en la página 9 se diçe que

de Almeyda, caballero de la primera sangre de aquel Reino, y que le estuviera mejor ser menos conocido, si nació para manchar la que tantos abuelos suyos derramaron en estas empresas. Prevínosele desde Castilla el descrédito que le amenaçava... y por dársele ensanche a que libremente obrara, sin otra atención que a su misma gloria y a la conservación de la Religión Católica en aquella ciudad, le apartaron en esta negociación de la obediencia que debía a su Rey y natural señor [Felipe IV, para Mascareñas y los castellanos]; y se le avisó que, abstrayendo de este punto y de la entrega de esta plaza a su verdadero dueño, tratasse solamente de conservarla en la obediencia de la Iglesia Católica; y que con esta acción... se valiesse de los socorros de los puertos de España..." (Campaña de Portugal..., pp. 10-11). En resumen, los castellanos estaban dispuestos a apoyar a los "rebeldes" portugueses de Tánger, si se oponían a permitir la entrada de los ingleses. 
se entregavan los templos cathólicos a luteranos y calvinistas para las ceremonias de sus abominables sectas; y en la 14 que los templos cathólicos se vieron hechos rezeptáculos de abominaciones $^{12}$.

Y aunque estas son verdades christianas y constantes en nuestra santa fee, como no es del caso afear con vituperios la religión (aunque falsa) de aquellos con quien se profesa o afecta amistad, y como no conduçe al intento de la historia ni a ningún fin (antes puede conducir a inconvenientes) el prorrumpir en estas injurias y el irritarlos con ellas, pareze que fuera bien haberlas escusado, mayormente cuando ha enseñado ya la esperienzia haber sido de perjuiçio con esta misma naçión el haber usado en diferentes ocassiones de una palabra semejante en alguna orden de $\mathrm{Su} \mathrm{Mgd}$. Y finalmente, en el más descubierto rompimiento y furor de guerra con ingleses, no quedan otras palabras de que usar ni que añadir para culpar o significar la falsedad depravada de su religión.

\section{[Cuarto reparo]. $4^{\circ}$}

Díçese en la página 27 que gobernaba a la sazón las armas enemigas el Conde de Castañeda, el mismo que las mandaba por enero del año de 59 cuando dos exércitos, entrambos españoles, apostaron a cometer yerros y venció el que los hiço mayores. No pareze cordura en un escritor nuestro desacreditar descubiertamente las resoluziones y operaçión de un exército real de $\mathrm{Su} \mathrm{Mg}$, y gobernado por su primer ministro, cuando los contratiempos de la guerra son tantas vezes hijos del acaso y de los açidentes, y no del error. Y en summa, no tienen otra peor manera de contarlo que ésta nuestros mismos enemigos.

12 "El principal intento [de los rebeldes de Portugal] fue prevenirse de armas auxiliares, y como la contienda era con las armas Católicas llamaron a favor de las suyas las heréticas. Ajustaron el casamiento de $\mathrm{D}^{\mathrm{a}}$ Catalina, hija de los Duques de Bergança, con el Rey de Inglaterra..." (Campaña de Portugal..., p. 8). "Para salvar las vidas, o renunciar del todo la misericordia de su Rey, los autores de estas turbulencias se aligeraron de lo más precioso de sus conquistas [Tánger]. Cantaron con esto la vitoria, que con más razón debieran celebrar Luteranos y Calvinistas, a quienes se entregavan los Templos Católicos para las ceremonias de sus abominables sectas..." (p. 9). "No es ponderable a la piedad christiana lo que aquellos pobres ciudadanos [de Tánger] vieron y experimentaron... Los Templos Católicos, despojados de imágenes y ornamentos, se vieron al instante hechos cavallerizas, y receptáculos de abominaciones; sus vezinos maltratados; sus casas desde luego posseídas de otros; sus haziendas sin valor, y por esso malvaratadas; finalmente todo confusión, dolor y desdichas" (p. 14). 
[Quinto reparo]. 5 $5^{\circ}$

En la página 9 se diçe que era grandeza de esta Monarchía el que un rey tan poderoso como el inglés buscase para esposa una vasalla de $\mathrm{Su} \mathrm{Mgd}$, atenzión bien merezida del agasaxo y amparo que halló en España desterrado y perseguido de sus propios vasallos. No pareze que es nezessario para nada el accordarle al Rey de Yngalaterra (en tiempo de paz con él) que está cassado con una vasalla de $\mathrm{Su} \mathrm{Mg}$, aunque sea (como es) verdad.

Y menos nezesario pareçe el traher a la memoria la ingratitud con que en esto ha correspondido al hospicio y amparo de España, pues reconvenirle con la desatençión cuando ni él da, ni se le pide, satisfazión de ella no es otra cossa que authorizar la sinrazón y desairar más con la quexa la toleranzia que se ha tenido en esto, lo qual se haze menos en alguna manera con el olvido y la disimulazión ${ }^{13}$.

Todos los reparos de Solís se refieren a unos contados párrafos de las primeras páginas del libro, y su censura no afecta al núcleo, es decir la narración minuciosa de las operaciones militares de la campaña de 1662 en la frontera de Extremadura. Algunos de los puntos de la censura pecan, desde luego, de un puntillismo más que excesivo. Así, en el segundo reparo, sobre los títulos que el autor había puesto en la portada: "Escrito por D. Gerónimo Mascareñas. del Consejo de Estado de Su Mgd, y del supremo de Portugal...", es claro que Mascareñas no pretendía hacer creer que era miembro de dos Consejos distintos, y era hilar de Zoilo demasiado fino afirmar, como Solís, que "pareze que se excede, pues si digera «del Consejo de Estado de Portugal» no se hallara el reparo que se halla en dezir «del Consejo de Estado y del de Portugal», porque la letra y colocada allí pareze que haze dos diferentes Consejos". Tiquismiquis, en fin, de un secretario celoso de las atribuciones del organismo donde ejercía de burócrata ${ }^{14}$. Mayor rigorismo aún exhibe Solís (cuarto reparo) al protestar por un gracioso inciso de Mascareñas recordando que, en 1659, "dos

13 "Hízose también célebre este ajuste entre los enemigos de la Católica Monarquía, no advirtiendo que entre sus grandezas referían por desdoro que un Rey tan poderoso buscasse a una vassalla suya para esposa; atención bien merecida del agasajo, y amparo que halló en ella, desterrado y perseguido de sus propios vassallos" (Campaña de Portugal..., p. 9).

14 MASCAREÑAS, en cualquier caso, siguió utilizando la misma fórmula en otro libro publicado dos años después: Fray Juan Pecador... Su vida, virtudes y maravillas, M. Alegre, Madrid, 1665. 
exércitos, entrambos españoles [el portugués y el castellano], apostaron a cometer yerros y venció el que los hiço mayores". No dice mucho en favor de la objetividad del Solís historiador su criterio de que "no pareze cordura en un escritor nuestro desacreditar descubiertamente las resoluziones y operaçión de un exército real". Muy al contrario, Mascareñas ya había advertido en su dedicatoria al rey que: "siendo mi fin escrivir solamente el hecho de lo sucedido a las reales armas de V. M. en sus católicas empresas, no me toca más que referirlos como passaron en la verdad, sean unos, u otros, poco favorables o muy gloriosos". Podríamos empezar a entrever que en la disputa subyacen distintos modos de entender la tarea del historiador, pero seguramente nos equivocaríamos.

Los reparos más sustanciales son los que nos quedan por comentar, y es en ellos donde se aprecian con claridad las razones de la confrontación entre ambos escritores. Todos ellos se refieren a la inoportunidad "política" que Solís veía en afirmaciones de Mascareñas que podían perjudicar las relaciones con los ingleses, con quienes por entonces "se profesaba o afectaba amistad". Es cierto que los españoles pusieron muchas esperanzas en una alianza, o al menos en la neutralidad de la monarquía inglesa recién restaurada, en 1660, en cabeza de Carlos II. Era, pues, imprudente recordar que Felipe IV estuvo dispuesto a ayudar bajo cuerda al gobernador rebelde de Tánger a cambio de evitar la entrada del ejército inglés (primer reparo); que los ingleses al ocupar la ciudad cometieron desafueros dignos de herejes (tercer reparo); y que el Rey de Inglaterra al casarse con Catalina de Bragança lo hacía con una vasalla, por muy rebelde que fuese, del rey de España (quinto reparo). Pero estos reparos afectaban si acaso a la razón de Estado, o al simple oportunismo político, y no son reparos "historiográficos". Ello es tanto más evidente si se advierte que en el primer punto censurado, el "que se tiene por más principal", lo que a Solís le escandalizaba era, precisamente, que el historiador divulgase una "matheria" que "se trató y manejó por Estado con summo secreto y con el recato nezessario a la gravedad de ella". Lo que debía hacer "un escritor nuestro" era no sólo abstenerse de sacar "a la luz pública esta noticia", sino "paliarla coloreándola con pretextos que la desvaneziesen". Ese es el punto de vista, insistamos, propio de un político y no de un cronista. De un político, por otra parte, un tanto ingenuo. Las razones objetivas de la alianza angloportuguesa eran lo suficientemente sólidas 
como para imaginar que Inglaterra fuera a inclinarse por los intereses de Felipe IV; y suponer que las mayores o menores cortesías de los "escritores nuestros" tuvieran incidencia alguna en la actitud hostil inglesa en asuntos como los de Tánger y Dunkerque era pecar de beatífico. Lo que Solís pretendía ocultar, en cuanto a Tánger, era por otra parte, del dominio público ${ }^{15}$; como era también sentimiento general confiar en la gratitud de Carlos de Estuardo por la acogida que halló en España y Flandes en su etapa de fugitivo de la Inglaterra de Cromwell -quinto reparo ${ }^{16}$.

Más a favor de Mascareñas: al enfatizar los desmanes anticatólicos de los protestantes en Tánger, el cronista no hacía más que recurrir a un topos muy socorrido en la historiografía hispánica de su tiempo. Los sacrilegios cometidos por franceses y holandeses en Flandes en 1634 fueron la piedra angular argumentativa en toda la abundante producción histórico-panfletaria de una generación, la rotulada por Jover como "generación de 1635", que incluye entre muchos otros a Quevedo, Saavedra Fajardo, Pellicer, Guillén de la Carrera, y al propio Mascareñas, autor de unos Sucesos de Flandes en 1635 que permanecieron iné$\operatorname{ditos}^{17}$. Las profanaciones en Tirlemont fueron consideradas como materia historiable privilegiada, y su denuncia era claramente funcional para los intereses de la Monarquía hispánica ${ }^{18}$, como lo prueban los actos de desagravio celebrados en diversas ciudades y las muchas composiciones poéticas que se coleccionaron y publicaron, también como "obras de desagravio" religioso. Nada había, pues, de insólito en utilizar la narración histórica como instrumento de denigración del adversario, si el historiador hallaba materia para ello. Es lo que Mascareñas hace: el gobernador portugués de Tánger, y, por elevación, los Bragança son responsables de las graves ofensas contra la religión católica que cometen los ingleses, desde el momento en que les dan entrada en la plaza africana por razones de conveniencia política (la dote de doña Catalina). El futuro obispo de

15 Cf., por ejemplo, la carta de enero de 1662, en los Avisos de Jerónimo de Barrionuevo, ed. A. Paz y Melia, Madrid, 1893, t. 4, p. 410.

16 Véase ibid., pp. 266-270.

${ }^{17}$ La obra fue publicada, de forma poco satisfactoria, por el Marqués de la Fuensanta y Sancho Rayón, en Varias relaciones de los Estados de Flandes, M. Ginesta, Madrid, 1880, pp. 29-137.

18 Cf. M. S. Arredondo, "La espada y la pluma contra Francia en el siglo XVII: cartas de Quevedo y Saavedra Fajardo”, Criticón, 1992, núm. 56, 103-115. 
Segovia se limitaba a poner en evidencia la ilegitimidad de base de los usurpadores de Portugal, incapaces de defender su fe, y a añadir unos palmos a la altura ética de su soberano, presentándonos un Felipe IV dispuesto a sacrificar sus intereses inmediatos de acabar con la rebeldía, antes que permitir la entrada de los herejes en Tánger. Claro es que son razones políticas las que decidieron esa conducta, pero un historiador como Mascareñas no tenía por qué desaprovechar la baza de exhibir a la religión como primera víctima.

\section{HisTORIA Y POLÍTICA}

La controversia no refleja, pues, dos distintos modos de concebir la labor del historiador, sino las inconveniencias que un oficial del Consejo de Estado creía ver por la intromisión de un cronista de historia contemporánea en asuntos que afectaban al manejo de la política exterior de la Monarquía. Antonio de Solís era oficial de la Secretaría de Estado desde 1655, es decir varios años antes de ser nombrado Cronista de Indias, en enero de 1661, sin por ello renunciar al cargo anterior. Y todo parece indicar que Solís no inició hasta mucho más tarde sus tareas como cronista; la redacción final de la Historia de la conquista de México se demoró, en cualquier caso, hasta $1682^{19}$.

El propio nombramiento de Solís como "Cronista mayor de las Indias” puede parecernos hoy poco justificado. No sólo no había tenido don Antonio relación alguna con las Indias ni experiencia personal americana de ninguna especie, como las que sí poseía su antecesor en el puesto, Antonio León Pinelo. Tampoco había mostrado hasta la fecha el menor interés por la historia. Su elección debe interpretarse como una "merced", que premiaba sus méritos de bien reconocido autor teatral áulico y, con toda probabilidad, sus servicios antiguos de criado y secretario de un personaje tan influyente en la corte como el Conde de Oropesa. Había algo o mucho de verdad, malevo-

19 Cf. F. Serralta, "Nueva biografía...”, pp. 118, 128-131. Solís había renunciado, en favor de un hijo, a su puesto en la Secretaría de Estado alegando el mucho cuidado y "continua aplicación” del Cargo de Cronista de Indias, con orden de escribir "la Historia de aquellos reinos". Pero lo hace sólo en junio de 1665 . Por otra parte, al morir su hijo pocos meses después, Solís volvió a desempeñar ambos empleos (cf. ibid., pp. 104-106, y antes, L. A. Arocena, op. cit., pp. 86-89, y 460-462). 
lencias aparte, en el comentario de Mascareñas que ya hemos leído: "Su inteligencia en las materias de la Historia es sumamente corta, y en ninguna manera es ascenso natural passar de los chistes de las Comedias, que es su professión, al puesto de Coronista de un tan gran Monarca". Sorprende, sobre todo, que Solís fuera antepuesto a don José Pellicer, que también optaba al cargo. Pellicer sí era autor con una amplísima obra de historiador, por heteróclita que hoy nos parezca, así como de genealogista y tratadista político, amén de comentador gongorino... y trescientas cosas más. Poco convincentes parecen las razones alegadas por el Consejo de Indias para preterir a Pellicer, fundadas en que de ser nombrado tendría que desembarazarse de sus otras ocupaciones para ocuparse ex profeso de sus deberes como cronista, "porque los coronistas anteriores han dejado esta obra muy atrasada y conviene proseguirla sin intermisión"20. También Solís tenía otras ocupaciones, a las que no se le hizo renunciar, y añadiría otras nuevas al ordenarse como sacerdote en 1667, sin que contribuyese ciertamente a paliar el atraso en la elaboración de la historiografía indiana ${ }^{21}$.

En suma, Solís es un cronista accidental. Aunque supiera desenvolverse con brillantez en la redacción de la Historia de la conquista de México, su obra ha sido desde antiguo más apreciada como monumento estilístico que como historia propiamente dicha. Además de renunciar a "proseguir" la Historia de las Indias desde donde la había dejado Antonio de Herrera, Solís se de-

20 L. A. Arocena, op. cit., pp. 59 y 456, y F. Serralta, "Nueva biografía...”, p. 99. Por otra parte, Pellicer había aspirado al puesto de Cronista de Indias, ya antes de 1630, con gran escándalo de Tamayo de Vargas, y volvió a hacerlo en 1637. Tamayo en cartas a Uztarroz y Jiménez de Urrea alude despectivamente a "Pellicerillo" y lo tacha de "hombre loco, sin seso y desvanecido", a más de denunciar que se intitulara fraudulentamente Cronista del Reino de Aragón. Cf. A. Reyes, "Pellicer en las cartas de sus contemporáneos", RFE, 6 (1919), 268-282; incl. en Cuestiones gongorinas, Espasa, Madrid, 1927, pp. 209-232.

${ }^{21}$ Arocena (p. 60) dice: "Solís sirvió en el puesto de Cronista Mayor 25 años. Durante su gestión y por su personal esfuerzo la Historia General de las Indias no avanzó un solo paso del punto y tiempo en que la dejara Herrera. En este sentido, la preocupación y deseos del Consejo [de Indias] se vieron una vez más defraudadas". En efecto, según Arocena, el Consejo había manifestado siempre su deseo de que los nuevos cronistas continuaran las Décadas de Herrera, como se aprecia en los requerimientos a Tamayo de Vargas en 1628 y a León Pinelo en 1658 (pp. 48-49 y 58-59). 
sentendió de la visión totalizadora de su predecesor, es decir la que correspondía a su puesto de "Cronista General de las Indias", y optó por limitarse a reescribir una parte mínima de lo ya escrito, los tres primeros años de la conquista de Nueva España. Solís escribe su historia apoyado en predecesores de la importancia de Cortés, Gómara, Bernal Díaz del Castillo y Herrera, a los que nada añade de nuevo en cuanto a datos propiamente históricos, haciendo una hábil taracea de lo que encontró en sus fuentes y poniendo de su parte una excelente retórica adaptada al gusto de los lectores de su tiempo. No son convincentes las razones que esgrime para justificar su particular elección de historiar lo ya historiado, y resultan tortuosas y poco agradables de leer, por nada generosas, las censuras que escribe contra los autores a quienes debía toda su información, especialmente contra Díaz del Castillo. El prólogo "a los que leyeren" y los dos primeros capítulos donde expone su "credo" son, eso sí, un buen ejercicio de encarecimiento de la cura y puesta en valor de lo que se proponía hacer: atender a lo que redundase en "la grandeza de la historia" y al "primor de entretejer los sucesos". O, hablando en claro, "tejer" una "composición" literaria. Los elogios tributados a una obra tan leída y reimpresa hasta el siglo xx incluyen calificativos que a la vez que ponderan los méritos literarios anulan su valor historiográfico: la Historia de Solís es una "novela heroica", una "epopeya", un "poema épico en prosa", un "panegírico", etc. Las críticas, desde William Robertson, en el siglo XviII, hasta Alfonso Reyes y Enriqueta López Lira, aceptadas ya como tópicos de manual, subrayan la paradoja de un cronista que se desentendió de los papeles de archivo a su alcance y que no añade un solo dato a lo que ya estaba impreso ${ }^{22}$. Aunque Arocena nos previene contra el anacronismo de juzgar a Solís según criterios historiográficos que no eran los suyos ni los de su tiempo, concuerda con las críticas generales en cuanto a su falta de diligencia en el acopio de información, en su escaso sentido crítico, su tendenciosidad apologética, etc. Las críticas de signo ideológico se han centrado en la frialdad y poca simpatía con que son contemplados los vencidos; y tampoco puede despertarnos ya gran entusiasmo el parti pris de representar en Hernán Cortés un héroe gracianesco de cartón piedra, por muy rentable que eso haya sido para una posteridad hispánica repleta de admira-

22 Se proporciona una excelente panorámica de la recepción crítica de la obra de Solís en el libro de Arocena, pp. 259-275. 
dores de un Gracián casi nunca bien comprendido y muchas veces falseado ${ }^{23}$. Por otra parte, aunque se tengan en cuenta las limitaciones de la historia "humanista", modelo en el que se integra la obra de Solís, con sus arengas, paralelismos clásicos y demás recursos tipificados, es cierto que ya a fines del siglo XVII había otras maneras de entender y escribir la historia. Un buen contraejemplo es la propia obra de Mascareñas censurada por Solís. Sin renunciar a ciertos "primores" de estilo y sin pretender ninguna neutralidad ante los hechos narrados, la Campaña de Portugal sabe alternar la exposición de los motivos que rigen las conductas humanas con la atención minuciosa a los datos, incluso en lo más descarnadamente cuantitativo. Le importa sobre todo la cronología, el "quién, cómo y cuándo". Se conserva toda la documentación que Mascareñas reunió para componer su obra, y será fácil comprobar que hasta el dato más nimio está debidamente justificado y "contrastado". Claro está que a la Campaña de Portugal le falta la "grandeza" que a Solís le desborda, y que la Historia de la conquista de México tendrá siempre un interés abismalmente superior... incluso si, como concluye López Lira, "la obra en conjunto nos aleja de la verdad en lugar de acercarnos a ella" 24 .

Son, pues, lógicos los resquemores de Mascareñas ante las censuras de Solís. Un historiador "documentalista", ávido coleccionador de cartas, relaciones de sucesos e informes directos de toda índole, no podía aceptar la crítica de un cronista todavía inédito, y hasta entonces ágrafo absoluto en "materias de la Historia". Ni siquiera entra a discutir los reparos "mal sonantes" de quien sólo era un "particular". Liberado de tener que conceder beligerancia ninguna a Solís como historiador, Mascareñas basa su defensa primero en la proclamación orgullosa de su ortodoxia y capacidad como verdadero historiador, y pasa inmediatamente a descalificar a su antagonista por motivaciones "políticas". Igual que eran políticas, razones de Estado, como atinó a entender enseguida, las motivaciones de los reparos de Solís. Mascareñas eleva, desde luego, el tono de la polémica y acusa a su censor poco menos que del delito de "infidencia". Dice que sólo al tramitar la aprobación para

23 Es Arocena, pp. 188-196, quien postula con evidente acierto la dependencia de la imagen de Cortés, según Solís, respecto a El héroe de Gracián; y posiblemente otras obras del jesuita aragonés.

24 E. López Lira, "La Conquista de México y su problema historiográfico", Revista de Historia de América, 1944, núm. 18, p. 331. 
su libro supo que Solís era oficial de la Secretaría de Estado, aunque lo era desde hacía siete años, y que ello le escandalizó. Releamos: el saberlo "fue una de las novedades que me hizieron mayor dissonancia, porque yo no podía presumir que un criado de suma confidencia del conde de Oropesa, inmediato sucessor del Duque de Bergança, esté metido dentro de la Secretaría de Estado de la parte de España, manejando los papeles corrientes de Portugal, y siendo dueño de las noticias de Estado de toda Europa y de las correspondencias de los Embaxadores, en tiempo que todas las negociaciones se dan la mano con las materias de Portugal. No hay, Señor, pocos exemplares en el mundo de los malos efetos que han produzido semejantes confianças".

Tales insinuaciones en un memorial al Rey eran graves, y Mascareñas sabía bien lo mucho que podían perjudicar a Solís. La vinculación de don Antonio con el conde de Oropesa, don Duarte Álvarez de Toledo y Portugal, era en efecto estrecha y antigua. Entró a servirle como secretario hacia 1637, y permaneció al servicio de su casa hasta su muerte ${ }^{25}$. A don Duarte debió en gran medida Solís los empleos públicos de que disfrutó, incluyendo su puesto en el Consejo de Estado, y sembrar sospechas sobre la lealtad de su amo y mecenas era sembrarlas sobre la lealtad de don Antonio. La política de Felipe IV hacia los portugueses que permanecieron a su lado después de la rebelión, sobre todo hacia los más cualificados por su linaje o capacidad como militares, fue la de halagarlos y mantenerlos satisfechos a toda costa. Pero al mismo tiempo procuró siempre alejarlos de la frontera con Portugal. Así hizo con Melo (el general, no el escritor), a quien hizo servir, en Sicilia, y Flandes, con el marqués de Castel Rodrigo, embajador en Roma y luego gobernador en Flandes, y con varios jefes militares como don Felipe de Silva y otros a quienes destinó a Flandes, Italia o Cataluña. El conde de Oropesa fue enviado como virrey a Navarra poco después de estallar la rebelión (1642-1645), y más tarde ocupó el virreinato en Valencia (1645-1650), y en ambos puestos ejerció Solís como su secretario. Quiere ello decir que aunque el Rey confiase en la fidelidad de don Duarte, no confiaba absolutamente o por lo menos no deseaba someter su lealtad a prueba, dado su parentesco con el "tirano de Portugal". En tales circunstancias las insinuaciones de

25 Cf. L. A. Arocena, op. cit., pp. 71-72, y F. Serralta, "Nueva biografía...”, pp. 65-69. 
Mascareñas caían en terreno bien abonado para la suspicacia. Cierto que don Jerónimo actuó sibilinamente y se limitó a exponer los riesgos de mantener a Solís en el Consejo de Estado y a aconsejar que se le trasladara al de Indias, por serle más "natural" ya que de él era cronista, en lo que no le faltaba lógica.

Es posible que al descalificar tan despectivamente a Solís como Cronista de Indias, Mascareñas respirara por la herida de la preterición de Pellicer, de quien fue amigo desde su llegada a Castilla. Es más probable, sin embargo, que don Jerónimo pensara en sí mismo al exaltar el "puesto de Coronista de un tan gran Monarca, empleo de tanta suposición entre los señores Reyes antiguos de estos Reynos que repetidas vezes eligieron para esta ocupación a los Arçobispos de Toledo, y en falta suya a otros Prelados y grandes cavalleros, a quien se fían seguramente la posteridad y fama de los Reyes". Mascareñas, obispo de Leiria y definidor de la Orden de Calatrava, cumplía plenamente los requisitos, si el oficio de Cronista real había de estar reservado a "Prelados y grandes cavalleros". La parte última del Memorial parece, al menos, la presentación formal de una candidatura: "Y ya que mi professión no me da lugar a servir a $\mathrm{V}$ $\mathrm{Mg}^{\mathrm{d}}$ con la espada, me he aplicado a hazerlo con la pluma, porque me causa gran dolor lo que leo en los libros estrangeros, y no merece desayres quien procura volver por el crédito de las acciones de su Rey. En esto me empleo todo el tiempo que me sobra de mis ocupaciones, y se ha luzido tanto mi trabaxo que los que han visto lo que yo tengo escrito del Reynado de V Mgd se admiran de que sea tarea de una sola vida".

Quien podía ser, según su concepto, cronista de toda la monarquía, y de hecho ya lo era "por libre", lo sería con mayor estímulo si el puesto se hacía oficial. Mascareñas, pues, al defenderse de las censuras de Solís aprovechó la ocasión para dejar bien claro que nadie le era superior en dignidad, lealtad y capacidad para ser el historiador del "gran Monarca".

\section{Su Majestad decide}

Solís, decíamos, representó el papel del "villano" en esta comedia de palabras y plumas, más que de capa y espada. Lo fue, sin duda, en cuanto que la agresión partió de él y actuó con doblez probada. Pero semejante "sentencia" sobre un caso que no sólo enfrentaba vanidades de distinto signo sería injusta 
si no se matiza algo más. Ya hemos visto que Mascareñas no era precisamente un espíritu angelical, y Solís, en cuanto burócrata de un organismo político, pudo muy bien creer que actuaba honradamente al oponerse a la publicación del libro de un portugués bien intencionado pero inoportuno.

La solución quedaba pendiente del rey, a quien ambas partes se remitían. Y habrá que reconocer que la decisión de un Felipe IV ya espectral, atormentado y abrumado por el fracaso, fue la menos mala de las posibles.

El memorial de Mascareñas (24 de febrero) y la consulta del Consejo de Estado (5 de abril) debieron de llegar al rey con pocas semanas de intervalo. Al no recibir ninguna respuesta, el Consejo remitió una nueva consulta un mes y medio después [A. G. Simancas, Estado, leg. 2.679]:

[Consulta del Consejo de Estado] De ofiçio. En Madrid, a 18 de Mayo de 1663

El Consejo de Estado, en que concurrieron el Duque de Alba y Marqués de Mortara,

Hace recuerdo a $\mathrm{V} \mathrm{Mg}$ de una consulta que en 5 de Abril remitió sobre la impressión de un libro que se dio a la estampa por Don Hierónimo Mascareñas.

Publicóse en 22 [de mayo]. D. Blasco de Loyola.

Señor,

En cinco de Abril pasado hiço el Consejo a V Mgd la consulta (cuya copia pone con esta en las reales manos de $\mathrm{V} \mathrm{Mg}{ }^{\mathrm{d}}$ ) con ocasión de haber dado a la estampa Don Gerónimo Mascareñas un libro intitulado Campaña de Portugal por la parte de Estremadura del año de 1662. Y porque hasta ahora no ha venido respondida, y tiene presente [el Consejo] la importancia de la materia, hace recuerdo a $\mathrm{V} \mathrm{Mg}^{\mathrm{d}}$ de ella para que si merecieren estimación los reparos hechos en el papel que fue con el libro (cuya copia también va aquí), con vista de todo resuelva $\mathrm{V} \mathrm{Mg}^{\mathrm{d}}$ lo que más fuere servido.

Madrid, a 18 de Mayo 1663 [siguen las rúbricas de los consejeros].

La respuesta, acotada al margen, suponía una nueva dilación, con la fórmula ritual: "Quedo con cuydado de tomar resolución en esto”. El rey no comunicaría nunca, sin embargo, ninguna resolución al Consejo por la razón sencilla de que ya la había tomado y comunicado directamente a la otra parte interesada. En efecto, en el memorial de Mascareñas la acotación marginal rubricada por el rey había dejado zanjada la cuestión sobre La cam- 
paña de Portugal: "Este libro podrá correr en la conformidad que está, y hállome con entera satisfaçión de vuestro celo de mi servicio, encargándoos continuéis con el travajo que decís tener comenzado".

La resolución real podemos verla como salomónica, si se tiene en cuenta que las insinuaciones contra Solís no tuvieron ninguna consecuencia y que el Conde de Oropesa siguió disfrutando del favor del monarca. Solís prosiguió su carrera de secretario y cronista, con ulteriores ascensos en el mismo Consejo de Estado, y Oropesa llegaría a ser uno de los personajes de más relieve en el reinado de Carlos II.

El Rey, pues, se limitó a no hacer nada. Mascareñas podía difundir intacto el libro, cuya edición completa decía estar dispuesto a hacer quemar, y se le animaba cortésmente a continuar sus labores historiográficas; pero no se hacía caso ninguno de sus iracundos ataques y denuncias implícitas contra Solís, ni se aceptaba su transparente propuesta de convertirse en cronista real. Solís, por su parte, salía libre de unos ataques y unas denuncias que tal vez no conoció nunca ${ }^{26}$, aunque en otras circunstancias podían haber costado caras; pero se le desautorizaba en su excesivo celo y hubo de resignarse a que el libro de Mascareñas se publicase con todos los párrafos que le parecían escandalosos. Es posible que limitándose a dejar pasar y no hacer nada, Felipe IV hiciera, fuese o no consciente de ello, lo más oportuno: poner, dejar a cada uno en su sitio ${ }^{27}$.

\author{
Jesús-Antonio Cid \\ Universidad Complutense
}

${ }^{26} \mathrm{O}$ tal vez sí los conoció. El memorial de Mascareñas se conserva hoy entre los papeles de las secretarías del Consejo de Estado, donde Solís tenía su puesto. Es de suponer que Mascareñas presentó en el Consejo su memorial autógrafo porque incluía el decreto real que autorizaba la publicación de su libro. De ser así, don Antonio no sólo tuvo que pasar por el trago de ver que su "diligencia secreta" había sido inútil, sino que pudo leer todo lo que Mascareñas había escrito en su contra.

${ }^{27}$ Es claro, en mi opinión, que A. CánOvas del Castillo atribuyó a la Consulta del Consejo de Estado sobre el libro de Mascareñas unas consecuencias que nunca tuvo, al suponer que esa norma era responsable en parte de la escasez de obras históricas dedicadas a la guerra hispano-portuguesa: "Con ocasión del libro que escribió D. Jerónimo Mascareñas respecto a la campaña de Extremadura de 1662, consultó precisamente a Felipe IV su Consejo de Estado que en adelante no se hiciesen publicaciones de tal índole, sin que con antelación declarara el mismo Consejo que no había en ello perjuicio" (Estudios del reinado de Felipe IV, Madrid, 1888, t. 1, pp. 4-5). 